\title{
Maxillofacial fracture due to traffic accidents in motorcycle riders with helmets
}

\author{
Erza Kurniawan*, Alwin Kasim*, Herman Hambali* \\ *Department of Oral and Maxillofacial Surgery Faculty Of Dentistry Universitas Padjadjaran, \\ Indonesia
}

\begin{abstract}
Introduction: Many of maxillofacial fractures in traffic accidents, primarily occurred to motorcyclists. The fractures are strongly influenced by the use of helmets, either half-face or fullface helmets. The objective of this research was to obtain information about the fractures occurred to motorcyclist with helmets. Methods: The research was designed as a descriptive study and conducted in Oral and Maxillofacial Surgery Department of Hasan Sadikin Hospital. Results: From January 2009 through November 2011, recorded as many as 116 out of 759 fracture cases (15.28\%). Based on its occurrence, male motorcyclist $(80.17 \%)$ was found more often than female $(19.83 \%)$. The study also recorded that based on the type of helmets, the accident occurred of those using half-face type $(86.33 \%$ ) and $13.67 \%$ to those using full-face type. Conclusion: Maxillofacial fractures in motorcycle accidents are recorded as many as 116 fracture cases. The most common type of maxillofacial fracture is a dentoalveolar fracture. Maxillofacial fracture more occurred in male.
\end{abstract}

Keywords: Maxillofacial fractures, helmets, motorcycle accidents.

\section{INTRODUCTION}

Trauma is an injury which causes loss psychologically or emotionally'. Physical trauma can affect to the soft tissue and hard tissue. Trauma on soft tissue usually in the form of abrasion and laceration, while in hard tissue is in the form of bone fractures ${ }^{2}$.

Fracture on face the covers maxilla, mandible, and the upper third of the face ${ }^{3}$. Main causes of jaw fracture are from fight, road accidents, fall and during sport activities. Jaw fracture often occurs mainly in men between the ages of 15 and 35 years and two times more frequently in the mandible than in the maxilla ${ }^{4}$.
Susceptibility to trauma facial skeleton due to suture line, foramina, the thin wall of the sinuses that cause some facial areas prone to fracture. The tendency of mandibular fractures due to protruded mandibular position compare to othe facial bones. Weak mandibular area include subcondylar, angle of the mandible and mentalist. Fractures in subcondylar is commonly found in children, whereas the angle fractures are more common in adolescents and young adults ${ }^{5}$.

The most common cause of maxillofacial fractures are from traffic accidents. Traffic accidents are one of non-communicable disease control based Kepmenkes 116 / Menkes / SK / VIII / 2003. According to the Department of 
Transportation Indonesia, traffic accidents became the third cause of death in Indonesia. Based on Health Research and Development Agency Department of Health, 25 percent of people who died in traffic accidents are motorcyclists and as much as 28 percent of the accident victims suffer head injuries. A large number of traffic accidents that cause maxillofacial fractures was also influenced by the use of a helmet that does not meet the standards in accordance with the applicable ISO standards.

Maxillofacial fractures caused by trauma in many traffic accidents are common in motorcyclists. Factors that influence the occurrence of maxillofacial fractures in motorcyclists in traffic accidents is the use of a helmet.

Half face helmet has a construction piece that closes the head to the front of the neck and close the ears, so as to protect the skull while full-face helmet has a shape that closes above the head, the neck and the mouth so as to protect the maxilla and the mandible of trauma. Use of half face

helmet has a higher risk to cause fracture maksila fasial as the construction helmet does not protect the mouth, meanwhile using a full face helmet has a lower risk to cause maxillofacial fractures because it's construction that can cover the full mouth. Helmets that standard must have a shell, protective coating inside to absorb impact energy, face shield, comfort pads, lining belts, brace, strap holders, cover the chin, pet, cover the lower face, the ventilation holes, holes for hearing, helmet net, and the base plane of the head.

\section{METHODS}

This type of research is a descriptive survey method. Data obtained from the medical records of cases of maxillofacial fractures in a traffic accident on a motorcyclist wearing a helmet at the Hospital Dr. Hasan Sadikin. Descriptive research is a problem-solving method by describing the state of the subject and object of research at the present time based on the facts available.

Data is obtained by collecting cards medical records of patients at the Oral Surgery Hospital, Dr. Hasan Sadikin range from January 2009 November 2011. Patient data diagnosed from the maxillofacial fractures due to traffic accidents on motorists who use helmets was taken.
The data collected is processed in the form of diagrams and tables frequency distribution and is presented in the form of percentage.

\section{RESULTS}

There are 759 patients with maxillofacial fractures at the Oral and Maxillofacial Surgery Hospital, Dr. Hasan Sadikin period January 2009-November 2011. Among the patients with maxillofacial fractures from motorcycles accident, only 116 people wore a helmet. (Table 1 ).

Categorized by gender, picture maxillofacial fractures as a result of a motorcycle accident occurs mostly in men with male numbered 93 people $(80.17 \%)$ and women 23 people $(19.83 \%)$.

Table 3 shows that maxillofacial fractures by anatomical location occurs largely in dentoalveolar (54.68\%) and the lowest percentage occurred in nasal $(0.72 \%)$

Based on table 4 shows that the maxillary fractures as a result of a motorcycle accident based on the location of anatomical mostly in Lefort II (62.50\%). Table 5 shows the mandibular fractures as a result of a motorcycle accident based on the location of anatomical mostly occurs in parasimfisis $(42.86 \%)$ and no fractures that occur in the mandibular rami.

Table 1. Distribution of maxillofacial fracture patients motorcycle accident in oral and maxillofacial surgery hospital, dr. Hasan sadikin period January 2009 - November 2011

\begin{tabular}{ccc}
\hline \multirow{2}{*}{ Year } & $\begin{array}{c}\text { Maxillofacial fracture } \\
\text { patients }\end{array}$ & Percentage (\%) \\
\cline { 2 - 2 } & Motorcycle accident & \\
\hline 2009 & 34 & 29.31 \\
2010 & 38 & 32.76 \\
2011 & 44 & 37.93 \\
\hline Total & 116 & 100 \\
\hline
\end{tabular}

Table 2. Distribution of patients maxillofacial fracture motorcycle accident by gender period January 2009 November 2011

\begin{tabular}{|c|c|c|}
\hline \multirow{2}{*}{ Gender } & Maxillofacial fracture patients & \multirow{2}{*}{$\begin{array}{c}\text { Percentage } \\
\text { (\%) }\end{array}$} \\
\hline & Motorcycle accident & \\
\hline Male & 93 & 80.17 \\
\hline Female & 23 & 19.83 \\
\hline Total & 116 & 100 \\
\hline
\end{tabular}


Table 3. Distribution of maxillofacial fracture cases motorcycle accident based anatomical location

\begin{tabular}{llllll}
\hline Year & Dentoalveolar & Maxillary & Mandible & Zigoma & Nasal \\
\hline 2009 & 19 & 7 & 12 & 0 & 0 \\
2010 & 28 & 5 & 12 & 2 & 0 \\
2011 & 29 & 4 & 12 & 8 & 1 \\
Total & 76 & 16 & 36 & 10 & 1 \\
\hline Percentage (\%) & $\mathbf{5 4 , 6 8 \%}$ & $\mathbf{1 1 . 5 1 \%}$ & $\mathbf{2 5 . 9 0 \%}$ & $\mathbf{7 . 1 9 \%}$ & $\mathbf{0 . 7 2 \%}$ \\
\hline
\end{tabular}

Table 4. Distribution of maxillary fracture in motorcycle accident based on anatomy location

\begin{tabular}{lllc}
\hline In & Le Fort I & Le Fort II & Le Fort III \\
\hline 2009 & 1 & 6 & 0 \\
2010 & 4 & 1 & 0 \\
2011 & 0 & 3 & 1 \\
Total & 5 & 10 & 1 \\
\hline Percentage (\%) & $31.25 \%$ & $6250 \%$ & $6.25 \%$ \\
\hline
\end{tabular}

Table 5. Distribution of mandible fracture cases motorcycle accident based anatomical location

\begin{tabular}{ccccccc}
\hline Year & Symphysis & Parasymphysis & Corpus & Condyle & Ramus & Angle \\
\hline 2009 & 3 & 5 & 1 & 4 & 0 & 1 \\
2010 & 1 & 8 & 1 & 3 & 0 & 4 \\
2011 & 3 & 8 & 3 & 3 & 0 & 1 \\
Total & 7 & 21 & 5 & 10 & 0 & 6 \\
\hline Percentage (\%) & $14.29 \%$ & $42.86 \%$ & $10.20 \%$ & $20.41 \%$ & $0,00 \%$ & $12.24 \%$ \\
\hline
\end{tabular}

Table 6. Number of cases of maxillofacial fracture motorcycle accident fractures according to different anatomical location and the type of helmet used

\begin{tabular}{lll}
\hline Location Fractures & Half Face & Full Face \\
\hline Maxillary & 13 & 3 \\
Mandible & 31 & 5 \\
Dentoalveolar & 67 & 9 \\
Zigoma & 8 & 2 \\
Nasal & 1 & 0 \\
Total & 120 & 19 \\
\hline Percentage (\%) & $86.33 \%$ & $1367 \%$ \\
\hline
\end{tabular}

Based on the result, the number of cases of maxillofacial fractures as a result of a motor accident occurs more frequently in half face helmet with the number of 120 cases than full face helmet, with the number of 19.

\section{DISCUSSION}

The results in Table 1 show that the number of patients with maxillofacial fractures as a result of a motorcycle accident that handled part of the department of Oral and Maxillofacial Surgery Dr. Hasan Sadikin period January 2009 - November 2011 a total of 116 people from 759 people with fractures. By gender, patients with maxillofacial fractures due to motorcycle accidents most often occur in patients with male, $80.17 \%$ and women only $19.83 \%$, with a ratio of $3: 1$ (Table 2 ) because there are more male riders on the road.

Based on the type of helmets used, maxillofacial fractures as a result of a motorcycle accident a lot going on motorists who used half face helmet consists of $86.33 \%, 13.67 \%$ in the one who use full face helmet. This is due to the helmet construction of half face helmet that can't withstand the collisions that lead to fractures. Mandible fracture is influenced by a prominent position on the face.

The ability of a helmet to protect the head is limited, but should still be considered due to the use of a helmet can reduce the amount of collisions received by the head. The helmet is designed to reduce the collision by altering the kinetic energy through deformation and spreading the collision force. 
Based on the research results, maxillofacial fracture still occur in full face helmet holder, because it is influenced by various factors such as the magnitude of the collision, the direction of impact, and the quality of the material of the helmet. The amount of power received by the helmet will be tempered by the bearing and spread to the entire surface of the helmet, but when the helmet is not capable of receiving power is too large, the helmet will be destroyed and the power will be received by the face, causing fractures in the bones of the face. Lefort II maxillary fractures are the most common cases reported, because of the thin bones and cavitis in nasal and maxillary bones which is more prone to fracture during a collision.

Based on the 2009 DC Thompson study found significantly helmet to protect the face from a facial injury. Protection helmet covers from various causes such as falls and collisions with stationary objects and moving. Helmets reduce the risk of head injury by $85 \%$, amounting to $88 \%$ of brain injuries and severe brain injury by at least $75 \%$. Impact protection helmets for facial injuries was $65 \%$ for the upper and mid-face region. To the motorcyclists of all ages should be encouraged to wear a helmet.

The results of the study, mandibular fractures in motorcycle accident occurs more common than maxillary fractures. The percentage of mandibular fractures as a result of a motorcycle accident is $25.90 \%$ while the fracture of the maxilla was $11.51 \%$. The tendency of mandibular fractures on motorists who half face helmet also influenced by the anatomical shape of the mandible as it is more prevalent than any other facial bones. The weaker mandibular area include subkondilus, angle of the mandible and mentalist. Fractures subcondyle commonly found in children, whereas the angle fractures are more common in adolescents and young adults (Pederson, 1996). Results showed dentoalveolar fracture is the most common among motorcyclists. It is due to the thin alveolar bone and the contour of the central incisor teeth. During a collision, half face helmet is not capable of protecting the mouth against collision, which caused dentoalveolar fractures. However, full face helmet also will stand a risk of causing dentoalveolar fractures too, sometimes due to the unfit helmet or when the collision force is higher.

\section{CONCLUSION}

Maxillofacial fractures in motorcycle accidents are recorded as many as 116 fracture cases. The most common type of maxillofacial fracture is a dentoalveolar fracture. Maxillofacial fracture more occurred in male.

\section{REFERENCES}

1. Dorland, WA Newman. Dorland Medical Dictionary. 29. Issue Jakarta: ECG. 2002. p. 2277.

2. Fonseca RJ. Oral and Maxillofacial Surgery 1. $3^{\text {rd }}$ ed. New York: Thieme, Stuttgart. 2005. p. 359-60.

3. Kruger OG. Oral and MaxillofacialSurgery.St. Louis, Toronto. The CV. Mosby Co. 1984. p. 386.539.

4. Moore UJ. Principles of Oral and Surgery Maxillofacia Fifth edition.Australia: Blackwell Science Ltd. 2001. p. 191.

5. Pedersen GW. Textbook of Practical OralSurgery. Interpretation by drg. Purwanto. Jakarta: Book Publishers EGC. 1996. p. 233, 18. 